\title{
Electromagnetic response of the mantle to long-period geomagnetic variations over the globe
}

\author{
Yoshimori Honkura and Masaki Matsushima \\ Department of Earth and Planetary Sciences, Tokyo Institute of Technology, 2-12-1 Ookayama, Tokyo 152-8551, Japan
}

(Received December 9, 1997; Revised May 18, 1998; Accepted May 19, 1998)

\begin{abstract}
Long-period electromagnetic response must be estimated to derive information on the electrical conductivity distribution within the deep mantle of the Earth. For this, we estimated the electromagnetic response function for long-period geomagnetic variations, on the basis of the $P_{1}$ approximation. The data used for analyses are geomagnetic daily mean values for 10 years (1965-1974) from 59 stations distributed over the globe and for about 20 years (1960-1980) from 9 stations. It turned out that the $P_{1}$ approximation generally holds except for the periods corresponding to annual and semi-annual variations. We also found that accurate estimation is difficult for periods longer than a few years, probably because of contamination due to secular variations of core origin.
\end{abstract}

\section{Introduction}

Time variations of the magnetic field originating outside the Earth induce electric currents inside the Earth, which in turn create the magnetic field observable outside the Earth. By separating these magnetic fields of internal and external origins we can estimate the electromagnetic response of the Earth. The response is usually measured as the ratio of internal to external parts, and it depends on the source of external magnetic field and the electrical conductivity distribution in the Earth.

Sources of magnetic variations of external origin are in the electric current systems in the Earth's magnetosphere and ionosphere. Most of long-period variations are generated by fluctuations in the ring current system located at about $3 \sim 4$ Earth's radii from the Earth's center. Since the current system is far from the Earth's surface, the magnetic field arising from such a current system is well represented by a zonal spherical harmonic constituent of degree one.

The appropriateness for such representation has so far been examined. In fact, Banks (1969) made analyses for frequencies in the range $3 \times 10^{-3}$ to $2.5 \times 10^{-1}$ cycle/day and showed that time variations of the magnetic field of external origin are mainly due to fluctuations of the ring current system. He then concluded that a single constituent of spherical harmonics, $P_{1}$, can well represent the geomagnetic variations, except for the annual variation, for which a $P_{2}$ spherical harmonic constituent is appropriate. In the meantime, Schultz and Larsen (1983) examined the geomagnetic daily mean data from 76 stations and concluded that representation in terms of a $P_{1}$ spherical harmonic constituent holds good for frequencies ranging from 0.01 to 0.2 cycle/day, although it does not for higher frequencies. On the other hand, McLeod (1994) analyzed first differences of monthly mean data and made

Copy right (C) The Society of Geomagnetism and Earth, Planetary and Space Sciences (SGEPSS); The Seismological Society of Japan; The Volcanological Society of Japan; The Geodetic Society of Japan; The Japanese Society for Planetary Sciences. spherical harmonic analysis up to degree and order three. He concluded that the magnetic field of external origin is expressed by zonal spherical harmonics; primarily $P_{1}$ for the continuous spectrum, primarily $P_{2}$ for the annual variation ( $\sim 2.74 \times 10^{-3}$ cycle/day), and primarily $P_{1}$ and secondarily $P_{3}$ for the semi-annual variation $\left(\sim 5.48 \times 10^{-3}\right.$ cycle/day $)$.

The electrical conductivity distribution in the mantle can be derived from the electromagnetic response function which is estimated through such analyses. Banks $(1969,1972)$ proposed a model for depths down to $2000 \mathrm{~km}$. Achache et al. (1981) claimed that a model proposed by Ducruix et al. (1980) is better than that of Banks, comparing the response functions computed for respective models. Constable (1993) took an average of response functions obtained by Roberts (1984) and Schultz and Larsen (1987), at periods between $10^{5}-10^{7}$ seconds $\left(8.64 \times 10^{-3} \sim 8.64 \times 10^{-1}\right.$ cycle/day $)$, and estimated the electrical conductivity structure of the mantle. McLeod (1994) obtained a response function for periods ranging from 2 months $\left(\sim 1.64 \times 10^{-2}\right.$ cycle/day $)$ to 2 years $\left(\sim 1.37 \times 10^{-3}\right.$ cycle/day) and found that it is consistent with an electrical conductivity model which indicates a conductivity value of about $10 \mathrm{~S} / \mathrm{m}$ at the core-mantle boundary.

The value of $10 \mathrm{~S} / \mathrm{m}$ at the core-mantle boundary is consistent with the result of laboratory measurements made by Shankland et al. (1993). They found that the electrical conductivity depends weakly on the temperature, the pressure and the composition, as far as the conditions appropriate for the lower mantle are considered. However, models of electrical conductivity distribution in the mantle are still controversial. As Achache et al. (1981) claimed, it is still a basic requirement to accurately determine the response function at long periods, particularly at periods of a few years. In this paper, we show the results of our analyses of long-period daily mean data at observatories over the globe, aiming at deriving the response function as accurately as possible. 
Table 1. List of magnetic observatories considered in this study.

\begin{tabular}{|c|c|c|c|c|c|}
\hline \multirow[b]{2}{*}{ Abb. Code } & \multirow[b]{2}{*}{ Site Name } & \multicolumn{2}{|c|}{ Geographic } & \multicolumn{2}{|c|}{ Geomagnetic } \\
\hline & & Latitude & Longitude & Latitude & Longitude \\
\hline $\mathrm{AAE}$ & Addis Ababa & 9.03 & 38.77 & 5.19 & 110.29 \\
\hline $\mathrm{ABG}$ & Alibag & 18.63 & 72.87 & 9.40 & 144.73 \\
\hline $\mathrm{AIA}$ & Argentine Island & -65.20 & 295.70 & -53.83 & 4.17 \\
\hline ALM & Almeria & 36.85 & 357.53 & 40.38 & 76.41 \\
\hline ANN & Annamalainagar & 11.40 & 79.68 & 1.49 & 150.50 \\
\hline $\mathrm{API}$ & Apia & -13.80 & 188.22 & -15.81 & 261.38 \\
\hline $\mathrm{AQU}$ & L'Aquila & 42.38 & 13.32 & 42.63 & 94.00 \\
\hline BLC & Baker Lake & 64.33 & 263.97 & 73.86 & 317.18 \\
\hline BNG & Bangui & 4.43 & 18.57 & 4.59 & 89.65 \\
\hline $\mathrm{CMO}$ & College & 64.87 & 212.17 & 64.88 & 257.75 \\
\hline CWE & Cape Wellen & 66.17 & 190.17 & 62.04 & 238.16 \\
\hline DAL & Dallas & 32.98 & 263.25 & 43.00 & 329.13 \\
\hline $\mathrm{DOB}$ & Dombas & 62.07 & 9.12 & 62.04 & 101.00 \\
\hline DRV & Dumont Durville & -66.66 & 140.01 & -75.41 & 232.28 \\
\hline ESK & Eskdalemuir & 55.32 & 356.80 & 58.22 & 83.95 \\
\hline FCC & Fort Churchill & 58.80 & 265.90 & 68.77 & 324.54 \\
\hline FRD & Fredericksburg & 38.20 & 282.63 & 49.50 & 351.29 \\
\hline FUR & Fürstenfeldbruck & 48.17 & 11.28 & 48.59 & 94.36 \\
\hline GDH & Godhavn & 69.23 & 306.48 & 79.65 & 34.47 \\
\hline GUA & Guam & 13.58 & 144.87 & 4.17 & 214.03 \\
\hline $\mathrm{HAD}$ & Hartland & 50.98 & 355.52 & 54.37 & 80.08 \\
\hline HER & Hermanus & -34.42 & 19.23 & -33.53 & 81.71 \\
\hline $\mathrm{HON}$ & Honolulu & 21.32 & 202.00 & 21.31 & 267.71 \\
\hline HRB & Hurbanovo & 47.87 & 18.18 & 46.95 & 100.80 \\
\hline IRT & Irkutsk & 52.17 & 104.45 & 40.80 & 175.65 \\
\hline KAK & Kakioka & 36.23 & 140.18 & 26.21 & 207.03 \\
\hline KGD & Karaganda & 49.82 & 73.08 & 40.29 & 149.60 \\
\hline $\mathrm{KNY}$ & Kanoya & 31.42 & 130.88 & 20.70 & 199.13 \\
\hline LER & Lerwick & 60.13 & 358.82 & 62.29 & 89.58 \\
\hline LGR & Logrono & 42.45 & 357.50 & 45.81 & 78.31 \\
\hline
\end{tabular}

\section{2. $P_{1}$ Approximation}

The magnetic potential outside the Earth satisfies

$$
\nabla^{2} \Psi=0,
$$

and its solution can be written, in spherical coordinates $(r, \theta, \phi)$, as

$$
\Psi=a \sum_{l=1}^{\infty} \sum_{m=-l}^{l}\left\{e_{l}^{m}\left(\frac{r}{a}\right)^{l}+i_{l}^{m}\left(\frac{a}{r}\right)^{l+1}\right\} Y_{l}^{m}(\theta, \phi),
$$

where $a$ is the Earth's mean radius and $Y_{l}^{m}$ is a spherical harmonic function with degree $l$ and order $m$. The terms which contain coefficients $e_{l}^{m}$ and $i_{l}^{m}$ correspond to those due to sources outside and inside the Earth's surface, respectively.

The northward component $(X)$, the eastward component $(Y)$ and the downward component $(Z)$ of the magnetic field at the Earth's surface, $r=a$, are given as, 
Table 1. (continued).

\begin{tabular}{|c|c|c|c|c|c|}
\hline \multirow[b]{2}{*}{ Abb. Code } & \multirow[b]{2}{*}{ Site Name } & \multicolumn{2}{|c|}{ Geographic } & \multicolumn{2}{|c|}{ Geomagnetic } \\
\hline & & Latitude & Longitude & Latitude & Longitude \\
\hline LNN & Leningrad & 59.95 & 30.70 & 56.08 & 118.22 \\
\hline LOV & Lovo & 59.35 & 17.83 & 57.87 & 106.69 \\
\hline LRV & Leirvogur & 64.18 & 338.30 & 69.97 & 72.16 \\
\hline MBC & Mould Bay & 76.30 & 240.60 & 79.40 & 257.26 \\
\hline MBO & M'Bour & 14.40 & 343.02 & 21.01 & 56.18 \\
\hline MEA & Meanook & 54.62 & 246.67 & 61.98 & 302.55 \\
\hline MIR & Mirny & -66.55 & 93.02 & -77.07 & 149.07 \\
\hline MMB & Memambetsu & 43.90 & 144.20 & 34.20 & 209.47 \\
\hline MOS & Moscow & 55.48 & 37.32 & 50.71 & 121.41 \\
\hline NUR & Nurmijarvi & 60.52 & 24.65 & 57.69 & 113.46 \\
\hline $\mathrm{PAF}$ & Port aux Francais & -49.35 & 70.22 & -57.46 & 129.47 \\
\hline PAG & Panagyurishte & 42.52 & 24.18 & 40.65 & 104.39 \\
\hline RSV & Rude Skov & 55.85 & 12.45 & 55.64 & 99.49 \\
\hline SIT & Sitka & 57.07 & 224.67 & 60.22 & 276.69 \\
\hline SJG & San Juan & 18.38 & 293.88 & 29.76 & 4.44 \\
\hline SNA & Sanae & -70.30 & 357.65 & -63.86 & 45.11 \\
\hline $\mathrm{SSH}$ & She-Shan & 31.10 & 121.19 & 19.89 & 190.34 \\
\hline SSO & Shimosato & 33.57 & 135.93 & 23.21 & 203.51 \\
\hline THL & Thule/Qanaq & 77.48 & 290.83 & 88.87 & 11.14 \\
\hline THY & Tihany & 46.90 & 17.90 & 46.08 & 100.13 \\
\hline TOL & Toledo & 39.88 & 355.95 & 43.63 & 75.80 \\
\hline TRD & Trivandrum & 8.48 & 76.95 & -1.13 & 147.52 \\
\hline TSU & Tsumeb & -19.22 & 17.70 & -18.41 & 83.99 \\
\hline TUC & Tucson & 32.25 & 249.17 & 40.54 & 313.53 \\
\hline VAL & Valentia & 51.93 & 349.75 & 56.39 & 74.58 \\
\hline VOS & Vostok & -78.45 & 106.87 & -89.40 & 102.05 \\
\hline WIK & Wien-Kobenzl & 48.27 & 16.32 & 47.70 & 99.21 \\
\hline WNG & Wingst & 53.75 & 9.07 & 54.32 & 95.05 \\
\hline YAK & Yakutsk & 62.02 & 129.72 & 51.11 & 194.74 \\
\hline
\end{tabular}

$$
\begin{aligned}
& X=\left(\frac{1}{r} \frac{\partial \Psi}{\partial \theta}\right)_{r=a}, Y=\left(-\frac{1}{r \sin \theta} \frac{\partial \Psi}{\partial \phi}\right)_{r=a}, \\
& Z=\left(\frac{\partial \Psi}{\partial r}\right)_{r=a} .
\end{aligned}
$$

If the magnetic potential can be approximated only by the term of degree 1 and order $0, Y_{1}^{0}=P_{1}(\cos \theta)$, where $P_{1}$ is a Legendre function, the horizontal and the vertical components of the magnetic field can be written as

$$
X=-\left(e_{1}^{0}+i_{1}^{0}\right) \sin \theta, \quad Y=0, \quad Z=\left(e_{1}^{0}-2 i_{1}^{0}\right) \cos \theta
$$

Hereafter we treat this case as the $P_{1}$ approximation. The response function, $i_{1}^{0} / e_{1}^{0}$, for the $P_{1}$ approximation is then given as

$$
\frac{i_{1}^{0}}{e_{1}^{0}}=\frac{X \cos \theta+Z \sin \theta}{2 X \cos \theta-Z \sin \theta},
$$

in terms of the $X$ and $Z$ components.

\section{Data Analysis}

We first used daily mean data for 10 years (1965-1974) from 59 stations distributed over the globe. These data were selected under some criteria. First, long time-series 


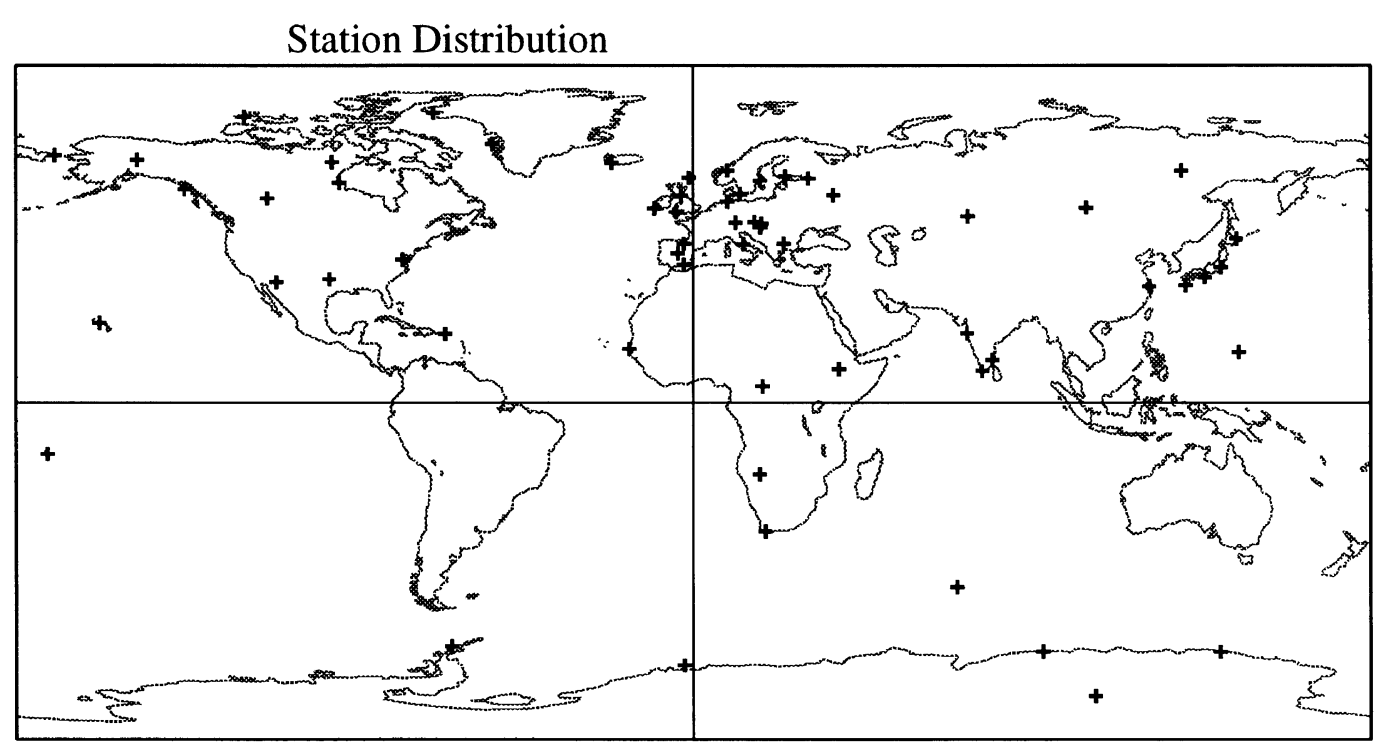

Fig. 1. Distribution of magnetic observatories considered in this paper.

data are required to examine low frequency variations. Second, simultaneous data from many stations are required to make global analyses. Third, station locations should be distributed as uniformly as possible over the Earth. Locations of stations considered in this paper are given in Table 1, and their distribution is shown in Fig. 1. Unfortunately, the third requirement is by no means satisfied as is evident by no entry from good stations existing in Australia, because of more emphasis on the other two requirements, which are more important in the present study.

We first made corrections and interpolations to the daily mean data. When some data points in time series data are largely different from their neighbor values, we regarded them as due to errors of some sort or severe geomagnetic disturbances, and we replaced them with the linearly interpolated values. When some portions of data are lacking, we interpolated them in the same way. However, the data with missing points for more than two months were rejected.

We then transformed the magnetic data sets consisting of the $X, Y$ and $Z$ components in geographic coordinates into those in geomagnetic coordinates, because the $P_{1}$ approximation holds for the geomagnetic coordinates. Since time series data covering 1965-1974 are used, the geomagnetic pole was determined from DGRF 1970, in which the Gauss coefficients are given as $g_{1}^{0}=-30220 \mathrm{nT}, g_{1}^{1}=-2068 \mathrm{nT}$, and $h_{1}^{1}=5737 \mathrm{nT}$. In the $P_{1}$ approximation, the $Y$ component of the geomagnetic field should be very small. Hereafter we regard the $X$ component as the horizontal component of the magnetic field.

We first removed a linear trend from time series data, and then applied a low-pass filter to the time series data to cut variations of periods shorter than 24 days which are more vulnerable to effects of lateral conductivity variations at shallow depth, such as highly conducting seas.

We next applied FFT to the data thus processed to estimate a response function $i_{1}^{0} / e_{1}^{0}$ in the frequency domain. It turned out, however, that error estimates are so large that a certain robust method must be used. Here we applied a remote reference method as follows. The observed horizontal field at a station, consisting of a signal $H_{1}$ and a noise $N_{1}$, is conventionally related to the observed horizontal field at another station, also consisting of a signal $\mathrm{H}_{2}$ and a noise $\mathrm{N}_{2}$, as

$$
H_{1}(f)+N_{1}(f)=A^{\prime}(f)\left(H_{2}(f)+N_{2}(f)\right)
$$

where $f$ is a frequency. $A^{\prime}(f)$ is regarded as an approximate estimate of a frequency response function $A(f)$, which is equal to $A^{\prime}(f)$ in Eq. (6) only when $N_{1}=N_{2}=0$. By multiplying a complex conjugate of the observed horizontal field consisting of a signal $\mathrm{H}_{3}$ and a noise $\mathrm{N}_{3}$ at a remote reference point, $H_{3}^{*}+N_{3}^{*}$, to both sides of Eq. (6) and by taking an average, we have

$$
\left\langle H_{1}(f) H_{3}^{*}(f)\right\rangle=A^{\prime}(f)\left\langle H_{2}(f) H_{3}^{*}(f)\right\rangle,
$$

where $\left\langle H_{1}(f) H_{3}^{*}(f)\right\rangle$, for example, is the cross spectrum between $H_{1}$ and $H_{3}$. All the other terms vanish if the noises, $N_{1}, N_{2}, N_{3}$, are all independent of each other and also of the signals, $H_{1}, H_{2}, H_{3}$. Thus we obtain

$$
A^{\prime}(f)=\frac{\left\langle H_{1}(f) H_{3}^{*}(f)\right\rangle}{\left\langle H_{2}(f) H_{3}^{*}(f)\right\rangle} .
$$

$A^{\prime}(f)$ in Eq. (8) turns out to be identical to the response function $A(f)$. Similarly, a frequency response function for the vertical field, $B(f)$, can be derived as

$$
B(f)=\frac{\left\langle Z_{1}(f) H_{3}^{*}(f)\right\rangle}{\left\langle H_{2}(f) H_{3}^{*}(f)\right\rangle} .
$$

We can select $\mathrm{H}_{2}$ and $\mathrm{H}_{3}$ at any stations if noises are independent, but it is certainly better that noises in $\mathrm{H}_{2}$ and $\mathrm{H}_{3}$ are all small. We selected the horizontal field data at DAL (Dallas) as $\mathrm{H}_{2}$ and those at HAD (Hartland) as $\mathrm{H}_{3}$, because the data quality seems good at these stations. 

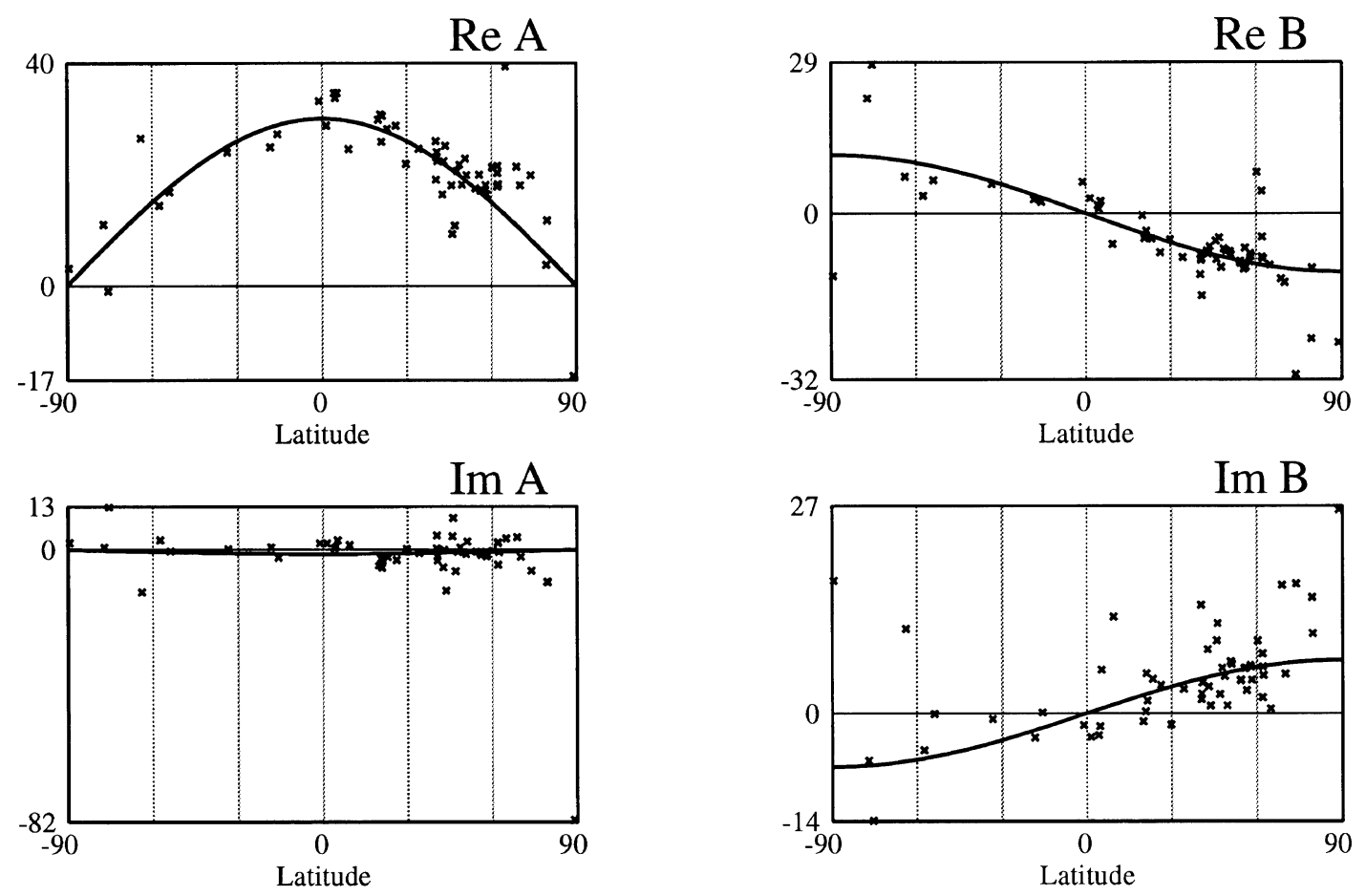

Frequency $=1.091 \mathrm{E}-2$ (cycle/day)

Fig. 2. Dependence of $A(f)$ and $B(f)$ on the geomagnetic latitudes for $1.091 \times 10^{-2}$ cycle/day. The solid curve denotes the best fitted $P_{1}$ distribution.
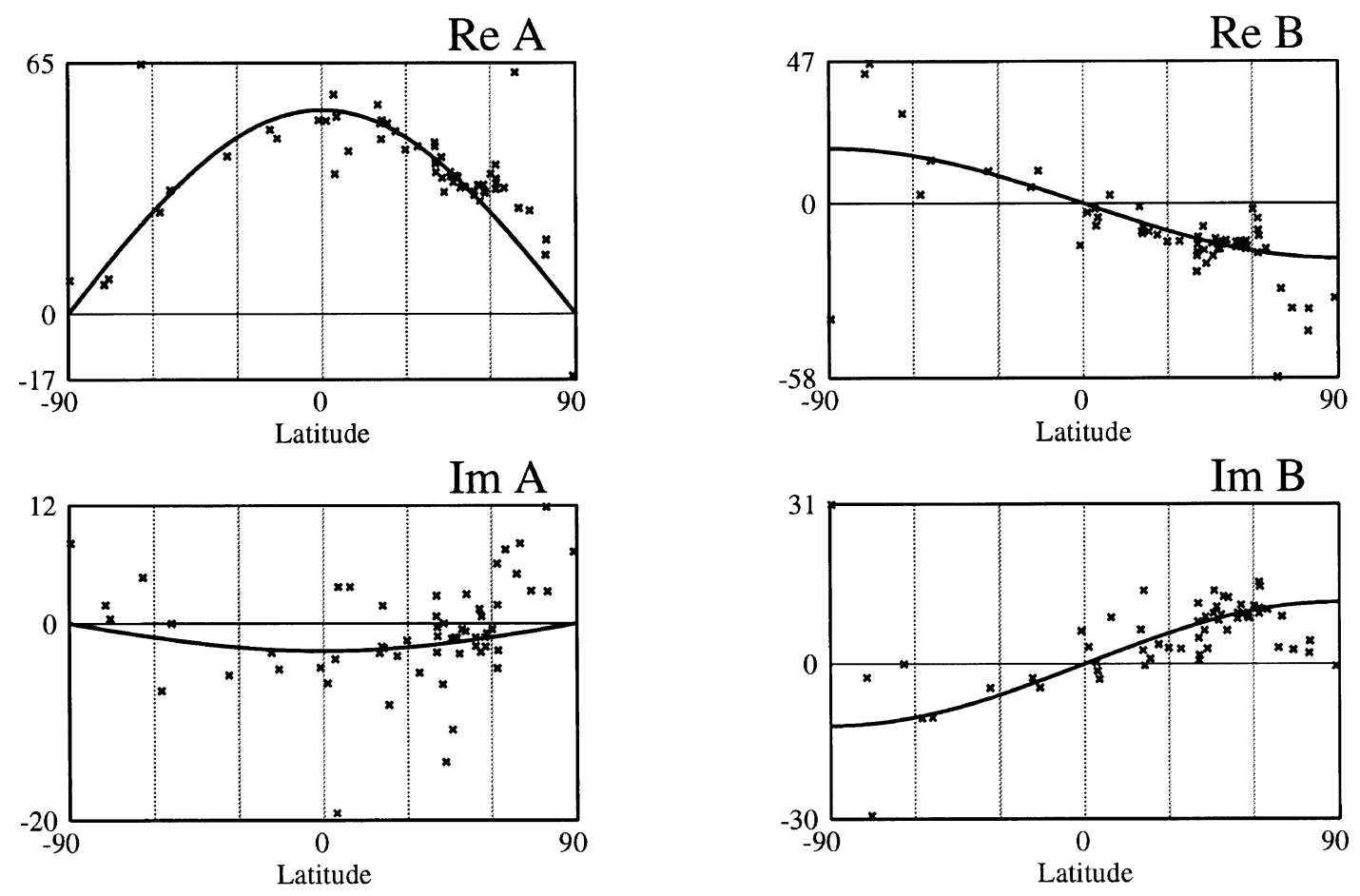

Frequency $=7.273 \mathrm{E}-3($ cycle/day $)$

Fig. 3. Dependence of $A(f)$ and $B(f)$ on the geomagnetic latitudes for $7.273 \times 10^{-3}$ cycle/day. The solid curve denotes the best fitted $P_{1}$ distribution. 

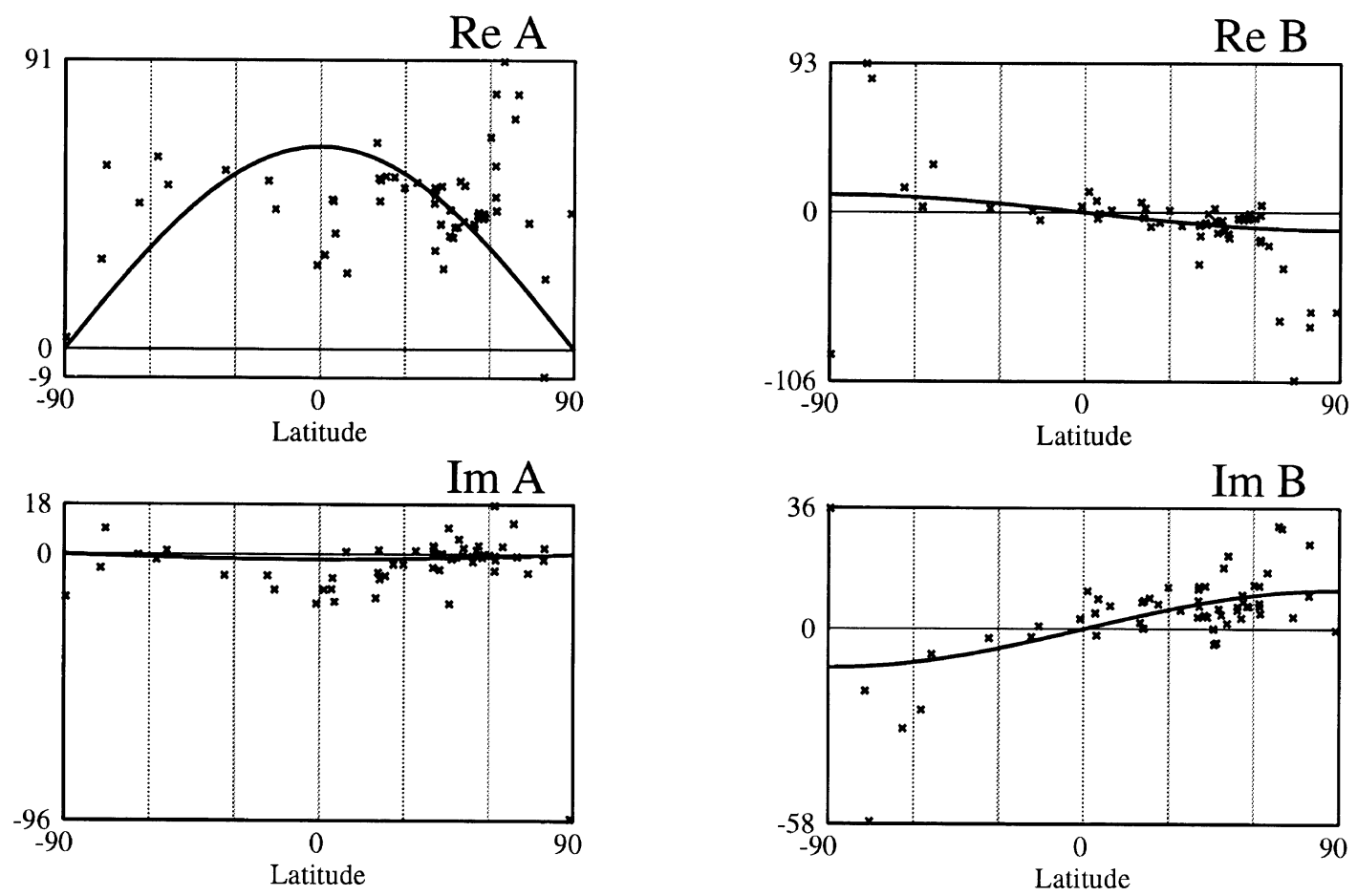

Frequency $=5.455 \mathrm{E}-3$ (cycle/day)

Fig. 4. Dependence of $A(f)$ and $B(f)$ on the geomagnetic latitudes for $5.455 \times 10^{-3}$ cycle/day. The solid curve denotes the best fitted $P_{1}$ distribution.
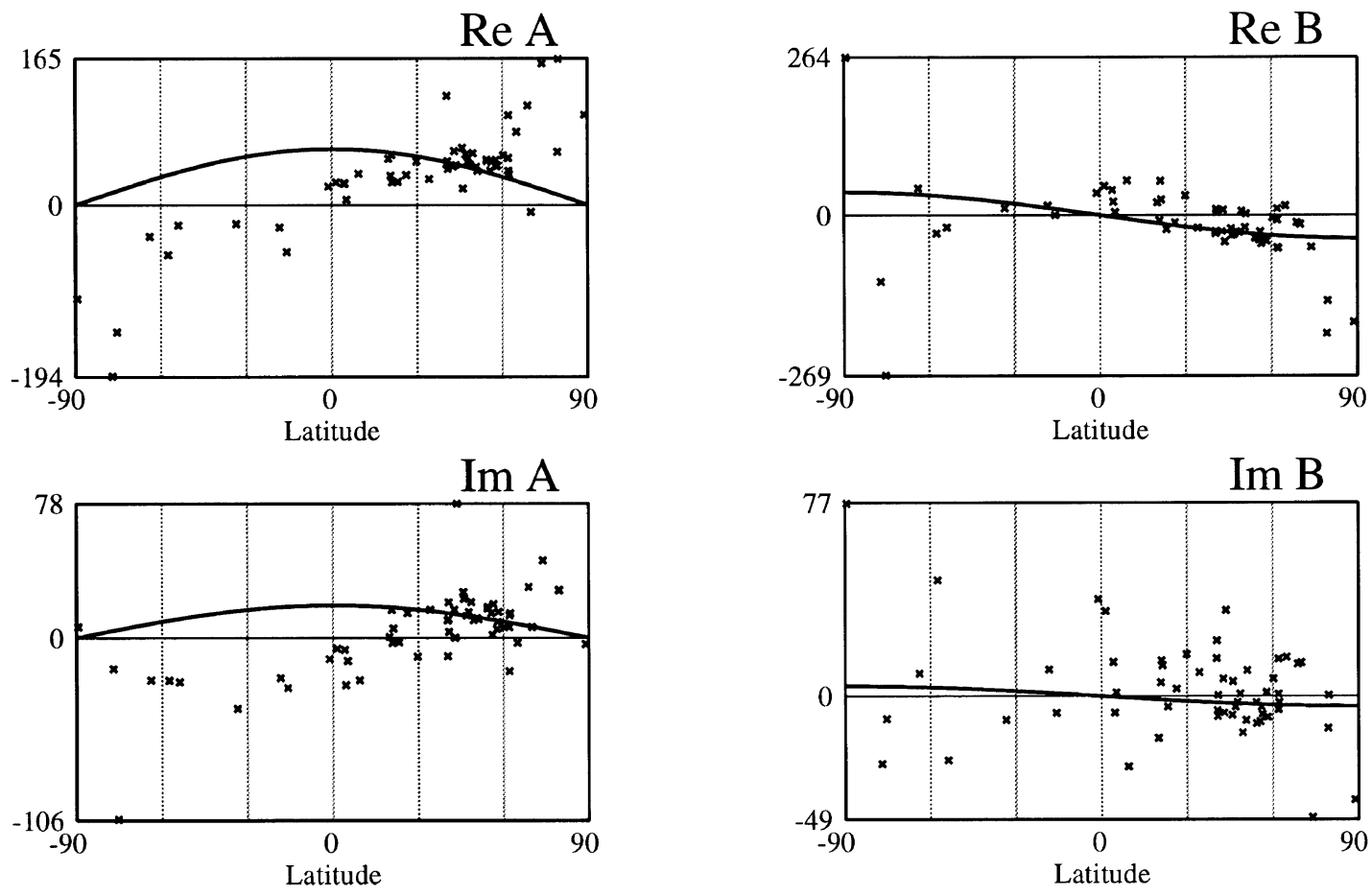

Frequency $=2.727 \mathrm{E}-3$ (cycle/day)

Fig. 5. Dependence of $A(f)$ and $B(f)$ on the geomagnetic latitudes for $2.727 \times 10^{-3}$ cycle/day. The solid curve denotes the best fitted $P_{1}$ distribution. 

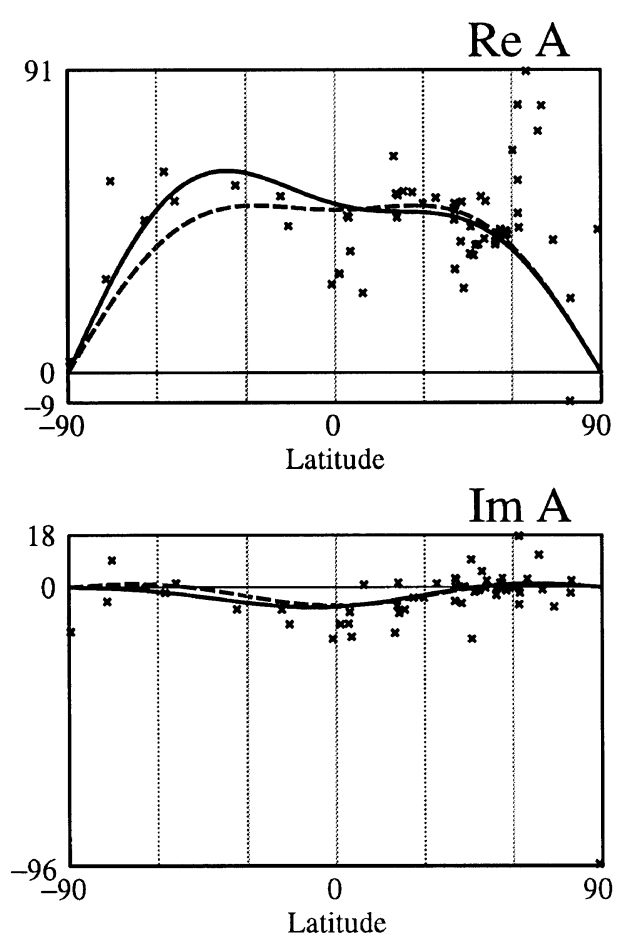

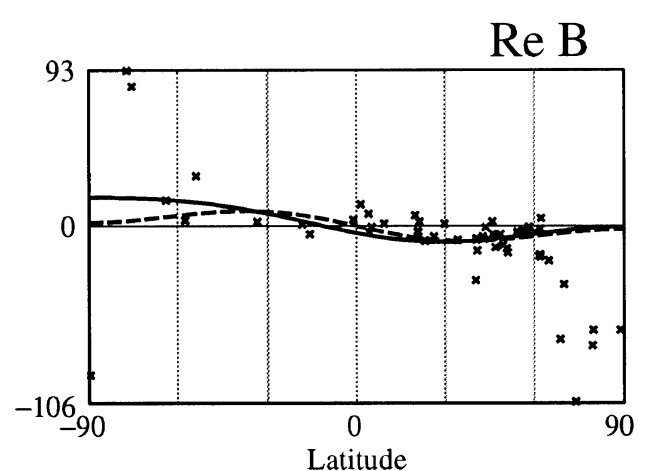

$\operatorname{Im} B$

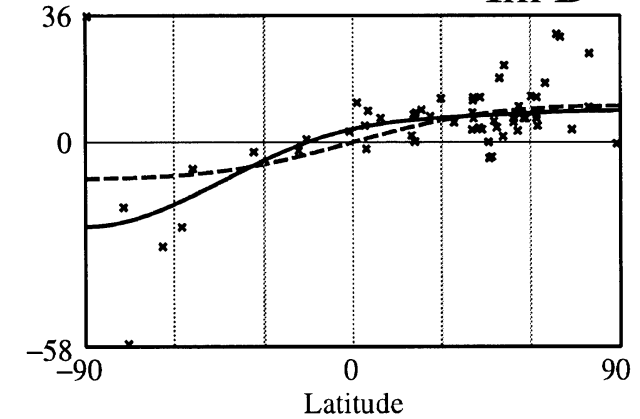

Frequency $=5.455 \mathrm{E}-3($ cycle/day $)$

Fig. 6. Dependence of $A(f)$ and $B(f)$ on the geomagnetic latitudes for $5.455 \times 10^{-3}$ cycle/day. The broken and solid curves denote the best fitted $P_{1}+P_{3}$ and $P_{1}+P_{2}+P_{3}$ distributions, respectively.

\section{Appropriateness of the $P_{1}$ Approximation}

The dependence of the horizontal and the vertical fields on the geomagnetic latitude is shown in Figs. 2-5 for four frequencies. Solid curves in respective figures indicate leastsquare fitting to $P_{1}$; in this case, $X$ (or $A$ ) and $Z$ (or $B$ ) components should be represented by $\sin \theta$ and $\cos \theta$, respectively. It should be noted here that $A(f)$ and $B(f)$ at high latitudes, $\theta<\pi / 6$ and $5 \pi / 6<\theta$ in the geomagnetic coordinates, are not used for fitting to $P_{1}$, since the $P_{1}$ approximation is not appropriate there because of the effect of the local current system in the auroral zone.

It turned out that the $P_{1}$ approximation holds fairly good for most of the frequencies, as shown for example in Figs. 2 and 3. Exceptional cases are the distributions for the frequencies close to semi-annual and annual variations, as shown in Figs. 4 and 5.

Currie (1966) pointed out that the annual and the semiannual variations are generated by different mechanisms. Banks (1969) found that the annual variation is well represented by a $P_{2}$ spherical harmonic constituent. They both presumed that ionospheric dynamo action would be responsible for the annual variation. On the other hand, Malin and Iş1kara (1976) pointed out that the annual variation is not due to the ionospheric current generated by dynamo action in the ionosphere, but due to north-south shift of the location of the ring current in the magnetosphere. According to McLeod (1994), the annual variation is primarily represented by $P_{2}$, and the semi-annual variation primarily by $P_{1}$ and $P_{3}$; the $P_{2}$ and $P_{3}$ constituents are regarded as due to the ionospheric current system.
In fact, the distributions of $A$ and $B$ shown in Fig. 4 for the frequency near the semi-annual variation cannot be well represented by $P_{1}$ only, even if scatter of data is taken into account. They are represented rather by the combination of $P_{1}$ and $P_{3}$ or by the combination of $P_{1}, P_{2}$ and $P_{3}$ as shown in Fig. 6. Which one of these combinations is better cannot be judged from the present data, but the contribution of both the $P_{1}$ and $P_{3}$ constituents is evident in Figs. 4 and 6; this is consistent with the claim of McLeod (1994).

Figure 5 also indicates that the annual variation cannot be represented by $P_{1}$ only. The distributions of $A$ and $B$ are better represented by $P_{2}$ or by the combination of $P_{1}$ and $P_{2}$ as shown in Fig. 7. The contribution of $P_{1}$ in the latter case is not marked and it may be an artifact due to noises.

In any case, we should exclude the semi-annual and annual variations for our further analyses based on the $P_{1}$ approximation. We can derive the response function $i_{1}^{0} / e_{1}^{0}$, from Eqs. (5), (8) and (9), as

$$
\frac{i_{1}^{0}}{e_{1}^{0}}=\frac{A(f) \cos \theta+B(f) \sin \theta}{2 A(f) \cos \theta-B(f) \sin \theta} .
$$

The resultant real and imaginary parts of response function are shown in Fig. 8. At high frequencies, they are estimates averaged over some frequency bands.

Because of data scatter indicated for example in Figs. 25 , error bars of the response function are large in spite of the data set covering 10 years at 59 stations. In order to increase the reliability, particularly at low frequencies, we further made analyses of geomagnetic field data covering a longer period at a limited number of stations and applied a 


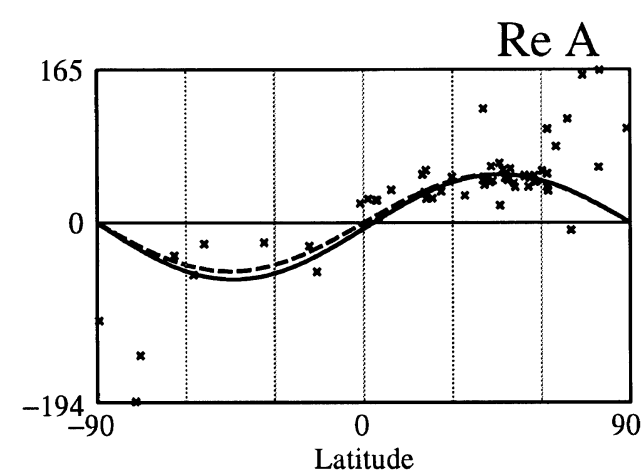

$\operatorname{Im} A$

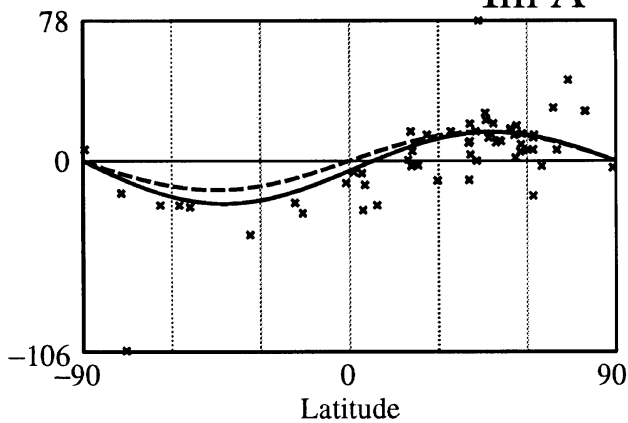

Re B

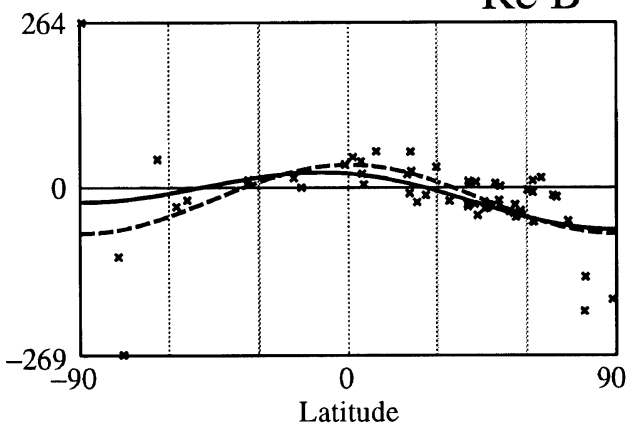

Im B

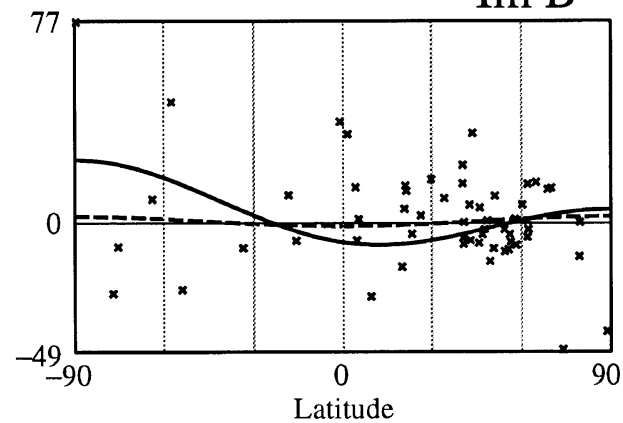

Frequency $=2.727 \mathrm{E}-3($ cycle/day)

Fig. 7. Dependence of $A(f)$ and $B(f)$ on the geomagnetic latitudes for $2.727 \times 10^{-3}$ cycle/day. The broken and solid curves denote the best fitted $P_{2}$ and $P_{1}+P_{2}$ distributions, respectively.

robust estimation, as described in the next section.

\section{Response Function}

Based on the $P_{1}$ approximation justified in the previous section, we analyze daily mean values covering about 20 years from 1960 to 1980 . Continuous data are obviously required for our present purpose, but only some of the stations can provide such a long sequence of data without any gaps. Inspection of Figs. 2-5 suggests that the data at some stations, which deviate from the overall distribution, might be noisy and hence responsible for large error bars of the response function estimates. We therefore selected only nine stations; they are ALM (Almeria), AQU (L'Aquila), FRD (Frederichsburg), FUR (Fürstenfeldbruck), IRT (Irkutsk), KAK (Kakioka), MOS (Moscow), WIK (Wien-Kobenzl), and WNG (Wingst).

The method of data analysis is basically the same as described in the previous section except for the remote reference method. Since we found that the horizontal component is of better quality and hence contains little noise, we may write the relation between $H_{1}$ and $Z_{1}$ at a station as

$$
Z_{1}(f)=A_{Z H}(f) H_{1}(f)+N_{1}(f)
$$

We then obtain a frequency response function $A_{Z H}(f)$ as

$$
A_{Z H}(f)=\frac{\left\langle Z_{1}(f) H_{2}^{*}(f)\right\rangle}{\left\langle H_{1}(f) H_{2}^{*}(f)\right\rangle},
$$

using $H_{2}(f)$ at another station regarded as a reference station.
Then the response function can be obtained as

$$
\frac{i_{1}^{0}}{e_{1}^{0}}=\frac{\cos \theta+A_{Z H}(f) \sin \theta}{2 \cos \theta-A_{Z H}(f) \sin \theta} .
$$

In order to increase the reliability for the response function estimates, we select only $A_{Z H}(f)$ 's that satisfy the following theoretically required relations,

$$
\operatorname{Re}\left(i_{1}^{0} / e_{1}^{0}\right)>0, \operatorname{Im}\left(i_{1}^{0} / e_{1}^{0}\right)>0, \text { and }\left|i_{1}^{0} / e_{1}^{0}\right|<1 / 2,
$$

for respective frequencies. We then apply the Tukey's biweight estimate for a robust estimate (Tukey, 1974), which is simply explained as follows. Instead of a usual weight, $w_{i}=\sigma_{i}^{-2}$, where $\sigma_{i}^{2}$ is the deviation of errors for the $i$ 'th datum, we used an effective weight

$$
w_{i}^{\text {eff }}=\left\{\begin{array}{cl}
{\left[1-\left(z_{i} / c s\right)^{2}\right]^{2} / \sigma_{i}^{2}} & \text { for }\left|z_{i}\right|<c s \\
0 & \text { for }\left|z_{i}\right| \geq c s
\end{array}\right.
$$

where $z_{i}=v_{i} / \sigma_{i} ; v_{i}$ is the $i$ 'th residual and $s$ the median of a set of $\left|z_{i}\right|$. A constant $c$ is changed according to Nakagawa and Oyanagi (1982);

$$
\begin{aligned}
& c=6 \text { for } \quad s \leq 5 \\
& c=10 \text { for } \quad 5<s \leq 100 \\
& c=20 \text { for } 100<s .
\end{aligned}
$$

This implies that less distinction is made between the data at the first stage of fitting, and sharp distinction is made at the final stage. 


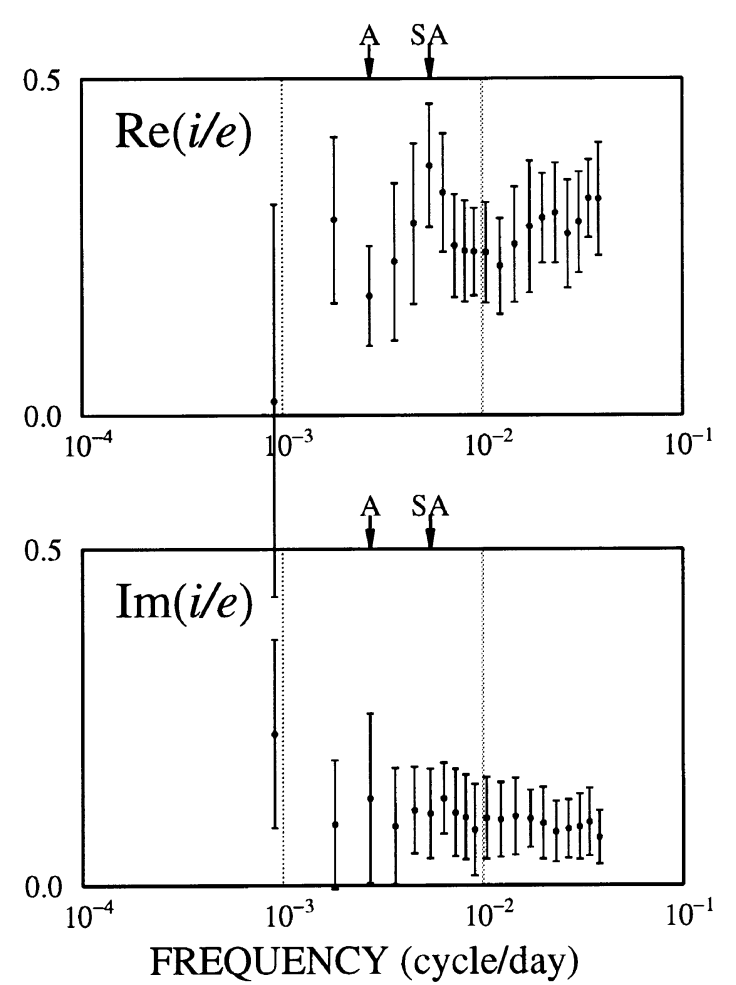

Fig. 8. A response function estimate derived from the daily mean data for 10 years. Marks 'A' and 'SA' correspond to the annual and the semi-annual frequencies, respectively.

Figure 9 shows the response function thus derived, and Table 2 gives the values of $\operatorname{Re}\left(i_{1}^{0} / e_{1}^{0}\right), \operatorname{Im}\left(i_{1}^{0} / e_{1}^{0}\right)$ and their errors. The $i_{1}^{0} / e_{1}^{0}$ data at the frequencies of $2.5 \times 10^{-4}$ and $5 \times 10^{-4}$ cycle/day did not satisfy the criterion (14) and hence they are not shown. We already noticed that the $P_{1}$ approximation is appropriate for most of the frequencies except for those corresponding to the semi-annual and the annual variations. In fact, the $i_{1}^{0} / e_{1}^{0}$ values at frequencies near $5.6 \times 10^{-3}$ cycle/day (the semi-annual variation) deviate from the overall trend. Also, less marked deviation is seen for frequencies near the annual variation. At frequencies lower than $10^{-3}$ cycle/day, the $i_{1}^{0} / e_{1}^{0}$ values seem to start to deviate from the extrapolated trend. We ascribe this as due to the effect of secular variations originating in the core.

\section{Discussion}

We have so far attempted to derive the electromagnetic response function for the Earth, from a set of long sequence of geomagnetic daily mean data, on the basis of the $P_{1}$ approximation. For discussion, we should first review the related studies.

Banks (1969) estimated the response function for frequencies ranging from $3 \times 10^{-3}$ to $2.5 \times 10^{-1}$ cycle/day. These data are shown with some other data in Banks (1972). Roberts (1984) obtained single-site estimates of the response function at 18 observatories for the periods of 2-200 days $\left(5 \times 10^{-3} \sim 5 \times 10^{-1}\right.$ cycle/day $)$, and pointed out that the responses at different stations are significantly different. This was ascribed to the effect of highly conducting oceans. Schultz and Larsen (1987) estimated a response function
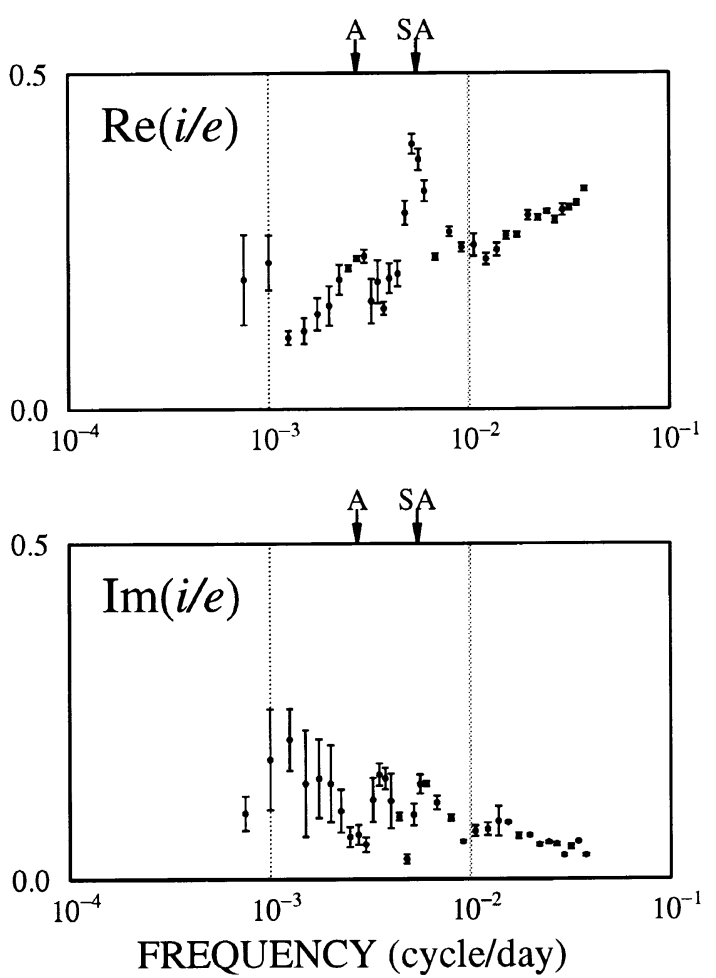

Fig. 9. A response function estimate derived from the daily mean data for about 20 years. Marks 'A' and 'SA' correspond to the annual and the semi-annual frequencies, respectively.

$(Z / H)$ and claimed that there must be lateral heterogeneity in the electrical conductivity at the depth of mid-mantle. Constable (1993) combined all these results, and considered a global response function, which is sensitive to the average radial electrical conductivity structure of the mantle. He then estimated the conductivity distribution of the mantle between $200 \mathrm{~km}$ and $2000 \mathrm{~km}$ depth from the response function for periods ranging from 3.25 days $\left(3.08 \times 10^{-1}\right.$ cycle/day) to 103 days $\left(9.71 \times 10^{-3}\right.$ cycle/day $)$.

In the meantime, McLeod (1992) analyzed first differences of annual mean data from 73 stations and found that the derived response for a 2-year period is consistent with a nearly insulating mantle underlain by a highly conducting core. McLeod (1994) analyzed first differences of monthly mean data from the same data source as in McLeod (1992). The response function for periods ranging from 2 months $\left(\sim 1.64 \times 10^{-2}\right.$ cycle/day) to 2 years $\left(\sim 1.37 \times 10^{-3}\right.$ cycle/day $)$ in McLeod (1994) agrees with that in Constable (1993) at the corresponding frequencies.

Now we compare the response function estimated in this paper with the others. We show all these response functions in Fig. 10; blue for Banks $(1969,1972)$, green for Constable (1993), red for McLeod (1994), and black for this paper.

At frequencies higher than about $5 \times 10^{-2}$ cycle/day, systematic discrepancy is seen between the response functions derived by Banks (1969) and Constable (1993). As Banks (1972) pointed out, the imaginary part of response function should theoretically be positive. Since we applied a low-pass filter to cut frequencies higher than $1 / 24$ cycle/day, we cannot say anything about the discrepancy. We only point out 
Table 2. Response function derived in this study.

\begin{tabular}{|c|c|c|c|c|}
\hline Frequency (cycle/day) & $\operatorname{Re}\left(i_{1}^{0} / e_{1}^{0}\right)$ & Error & $\operatorname{Im}\left(i_{1}^{0} / e_{1}^{0}\right)$ & Error \\
\hline $7.500 \times 10^{-4}$ & $1.925 \times 10^{-1}$ & $6.664 \times 10^{-2}$ & $9.844 \times 10^{-2}$ & $2.550 \times 10^{-2}$ \\
\hline $1.000 \times 10^{-3}$ & $2.178 \times 10^{-1}$ & $4.062 \times 10^{-2}$ & $1.782 \times 10^{-1}$ & $7.462 \times 10^{-2}$ \\
\hline $1.250 \times 10^{-3}$ & $1.067 \times 10^{-1}$ & $1.029 \times 10^{-2}$ & $2.076 \times 10^{-1}$ & $4.571 \times 10^{-2}$ \\
\hline $1.500 \times 10^{-3}$ & $1.168 \times 10^{-1}$ & $1.924 \times 10^{-2}$ & $1.424 \times 10^{-1}$ & $7.898 \times 10^{-2}$ \\
\hline $1.750 \times 10^{-3}$ & $1.416 \times 10^{-1}$ & $2.364 \times 10^{-2}$ & $1.500 \times 10^{-1}$ & $5.837 \times 10^{-2}$ \\
\hline $2.000 \times 10^{-3}$ & $1.537 \times 10^{-1}$ & $2.899 \times 10^{-2}$ & $1.423 \times 10^{-1}$ & $5.694 \times 10^{-2}$ \\
\hline $2.250 \times 10^{-3}$ & $1.925 \times 10^{-1}$ & $2.211 \times 10^{-2}$ & $1.018 \times 10^{-1}$ & $3.203 \times 10^{-2}$ \\
\hline $2.500 \times 10^{-3}$ & $2.096 \times 10^{-1}$ & $4.404 \times 10^{-3}$ & $6.302 \times 10^{-2}$ & $1.506 \times 10^{-2}$ \\
\hline $2.750 \times 10^{-3}$ & $2.238 \times 10^{-1}$ & $3.574 \times 10^{-3}$ & $6.621 \times 10^{-2}$ & $1.485 \times 10^{-2}$ \\
\hline $3.000 \times 10^{-3}$ & $2.273 \times 10^{-1}$ & $9.762 \times 10^{-3}$ & $5.156 \times 10^{-2}$ & $1.085 \times 10^{-2}$ \\
\hline $3.250 \times 10^{-3}$ & $1.607 \times 10^{-1}$ & $3.292 \times 10^{-2}$ & $1.183 \times 10^{-1}$ & $3.265 \times 10^{-2}$ \\
\hline $3.500 \times 10^{-3}$ & $1.894 \times 10^{-1}$ & $3.182 \times 10^{-2}$ & $1.558 \times 10^{-1}$ & $1.664 \times 10^{-2}$ \\
\hline $3.750 \times 10^{-3}$ & $1.499 \times 10^{-1}$ & $9.743 \times 10^{-3}$ & $1.501 \times 10^{-1}$ & $1.580 \times 10^{-2}$ \\
\hline $4.000 \times 10^{-3}$ & $1.946 \times 10^{-1}$ & $2.203 \times 10^{-2}$ & $1.166 \times 10^{-1}$ & $4.065 \times 10^{-2}$ \\
\hline $4.400 \times 10^{-3}$ & $2.013 \times 10^{-1}$ & $1.909 \times 10^{-2}$ & $9.314 \times 10^{-2}$ & $5.717 \times 10^{-3}$ \\
\hline $4.800 \times 10^{-3}$ & $2.917 \times 10^{-1}$ & $1.785 \times 10^{-2}$ & $2.977 \times 10^{-2}$ & $7.076 \times 10^{-3}$ \\
\hline $5.200 \times 10^{-3}$ & $3.947 \times 10^{-1}$ & $1.491 \times 10^{-2}$ & $9.609 \times 10^{-2}$ & $1.611 \times 10^{-2}$ \\
\hline $5.600 \times 10^{-3}$ & $3.718 \times 10^{-1}$ & $1.599 \times 10^{-2}$ & $1.416 \times 10^{-1}$ & $1.409 \times 10^{-2}$ \\
\hline $6.000 \times 10^{-3}$ & $3.249 \times 10^{-1}$ & $1.587 \times 10^{-2}$ & $1.425 \times 10^{-1}$ & $3.464 \times 10^{-3}$ \\
\hline $6.792 \times 10^{-3}$ & $2.261 \times 10^{-1}$ & $4.778 \times 10^{-3}$ & $1.139 \times 10^{-1}$ & $1.009 \times 10^{-2}$ \\
\hline $7.993 \times 10^{-3}$ & $2.636 \times 10^{-1}$ & $7.239 \times 10^{-3}$ & $9.168 \times 10^{-2}$ & $4.478 \times 10^{-3}$ \\
\hline $9.194 \times 10^{-3}$ & $2.401 \times 10^{-1}$ & $6.553 \times 10^{-3}$ & $5.580 \times 10^{-2}$ & $1.907 \times 10^{-3}$ \\
\hline $1.059 \times 10^{-2}$ & $2.437 \times 10^{-1}$ & $1.669 \times 10^{-2}$ & $7.163 \times 10^{-2}$ & $7.917 \times 10^{-3}$ \\
\hline $1.219 \times 10^{-2}$ & $2.229 \times 10^{-1}$ & $8.631 \times 10^{-3}$ & $7.464 \times 10^{-2}$ & $9.426 \times 10^{-3}$ \\
\hline $1.379 \times 10^{-2}$ & $2.368 \times 10^{-1}$ & $9.871 \times 10^{-3}$ & $8.617 \times 10^{-2}$ & $2.229 \times 10^{-2}$ \\
\hline $1.539 \times 10^{-2}$ & $2.581 \times 10^{-1}$ & $6.011 \times 10^{-3}$ & $8.450 \times 10^{-2}$ & $1.577 \times 10^{-3}$ \\
\hline $1.739 \times 10^{-2}$ & $2.590 \times 10^{-1}$ & $3.987 \times 10^{-3}$ & $6.419 \times 10^{-2}$ & $4.697 \times 10^{-3}$ \\
\hline $1.979 \times 10^{-2}$ & $2.879 \times 10^{-1}$ & $6.947 \times 10^{-3}$ & $6.516 \times 10^{-2}$ & $1.769 \times 10^{-3}$ \\
\hline $2.219 \times 10^{-2}$ & $2.844 \times 10^{-1}$ & $4.271 \times 10^{-3}$ & $5.114 \times 10^{-2}$ & $2.378 \times 10^{-3}$ \\
\hline $2.459 \times 10^{-2}$ & $2.938 \times 10^{-1}$ & $3.343 \times 10^{-3}$ & $5.440 \times 10^{-2}$ & $2.036 \times 10^{-3}$ \\
\hline $2.699 \times 10^{-2}$ & $2.815 \times 10^{-1}$ & $5.117 \times 10^{-3}$ & $5.176 \times 10^{-2}$ & $2.787 \times 10^{-3}$ \\
\hline $2.939 \times 10^{-2}$ & $2.961 \times 10^{-1}$ & $8.349 \times 10^{-3}$ & $3.551 \times 10^{-2}$ & $2.240 \times 10^{-3}$ \\
\hline $3.179 \times 10^{-2}$ & $2.995 \times 10^{-1}$ & $3.731 \times 10^{-3}$ & $4.808 \times 10^{-2}$ & $3.672 \times 10^{-3}$ \\
\hline $3.459 \times 10^{-2}$ & $3.062 \times 10^{-1}$ & $4.178 \times 10^{-3}$ & $5.590 \times 10^{-2}$ & $1.187 \times 10^{-3}$ \\
\hline $3.779 \times 10^{-2}$ & $3.279 \times 10^{-1}$ & $3.730 \times 10^{-3}$ & $3.550 \times 10^{-2}$ & $1.869 \times 10^{-3}$ \\
\hline
\end{tabular}

here that the response function derived in this paper agrees very well with that of Constable (1993) for the overlapping frequencies ranging from $1 \times 10^{-2}$ to $4 \times 10^{-2}$ cycle/day.

The response function of McLeod (1994) at lower frequencies agrees well with that in this paper, particularly for its real part. A big discrepancy exists between $\operatorname{Im}\left(i_{1}^{0} / e_{1}^{0}\right)$ values for $1.25 \times 10^{-3}$ cycle/day in this paper and that for $1.37 \times 10^{-3} \mathrm{cy}-$ cle/day in McLeod (1994), but the latter is within the error range in this paper. The discrepancy between the response function estimates corresponding to the semi-annual varia- 

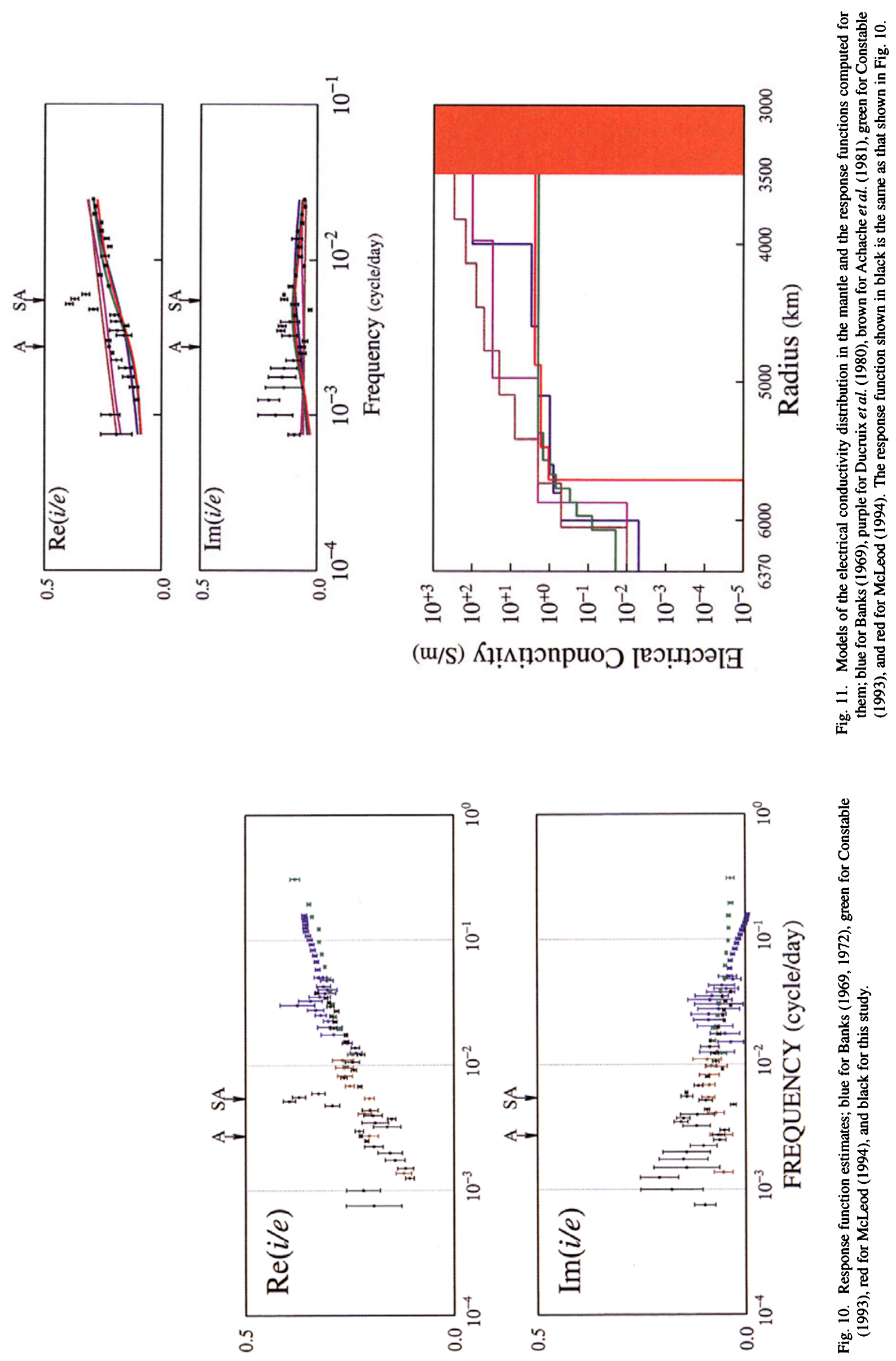
tion $\left(\sim 5.5 \times 10^{-3}\right.$ cycle/day) in this paper and in McLeod (1994) is obviously due to the $P_{1}$ approximation on which we relied in this paper. Malin et al. (1996) also pointed out that the response function for the semi-annual variation based on the $P_{1}$ approximation is misleading. The $P_{1}$ approximation also does not hold for the frequency corresponding to the annual variation, as clearly shown in Fig. 5. Nonetheless the response functions for the annual variation in this study and in McLeod (1994) agree with each other.

For frequencies lower than about $10^{-3}$ cycle/day, the effect of secular variations seems to appear. We therefore cannot rely on the response function, used throughout this paper, for such frequencies to estimate electrical conductivity distribution of the deep lower mantle. However, this information may be useful in that any whole mantle conductivity models should allow the core field of a period of one year or so to penetrate through the mantle to the Earth's surface, although a core field model of some sort would be required for this argument.

We finally consider some mantle conductivity models estimated so far, as shown in Fig. 11; blue for Banks (1969), purple for Ducruix et al. (1980), brown for Achache et al. (1981), green for Constable (1993), and red for McLeod (1994). In Fig. 11 we show, with the corresponding colors, the response functions computed for these models. These response functions can be classified into two groups; one is for Ducruix et al. and Achache et al., and the other for Banks, Constable, and McLeod. The significant difference between the two stems from the electrical conductivity at radii between $4000 \mathrm{~km}$ and $5000 \mathrm{~km}$. The conductivity values at this depth range are higher than $10 \mathrm{~S} / \mathrm{m}$ in the former group, whereas in the latter they are in the range between 1 and $3 \mathrm{~S} / \mathrm{m}$.

Comparing these response functions with that derived in this study as shown in black in Fig. 11, we may claim that the electrical conductivity at radii between $4000 \mathrm{~km}$ and $5000 \mathrm{~km}$ would be in the range between 1 and $3 \mathrm{~S} / \mathrm{m}$. This conductivity range is consistent with the result of laboratory measurements of Shankland et al. (1993). In order to estimate a more plausible electrical conductivity distribution in the mantle, an inverse method should be applied to the derived response function.

\section{Conclusions}

We analyzed daily means of geomagnetic field covering 10 years (1965-1974) from 59 stations distributed over the globe. Dependence of frequency response functions, $A(f)$ and $B(f)$, on the geomagnetic latitudes shows that the $P_{1}$ spherical harmonic constituent generally describes time variations of geomagnetic field of external origin with exceptions for the semi-annual and the annual variations.

We further analyzed geomagnetic daily mean data covering more than 20 years (1960-1980) from 9 stations, based on the $P_{1}$ approximation which was generally verified. Applying a robust estimation method, we derived an electromag- netic response function for the Earth. The response function thus derived is consistent with those of Constable (1993) and McLeod (1994). We also found that the response function for frequencies lower than about $10^{-3}$ cycle/day deviate from the extrapolated trend, probably due to contamination by the effect of secular variation arising from dynamo action in the Earth's core. With these limitations in mind, the derived response function can be used to estimate the radial electrical conductivity distribution of the whole mantle.

Acknowledgments. We express our sincere thanks to the staff at the Data Analysis Center for Geomagnetism and Space Magnetism, Kyoto University, Japan, for their assistance to acquire the geomagnetic field data. We are thankful to N. Matsuo, S. Ikura, and H. Yamazaki for their efforts to prepare the data set used in this paper. We thank an anonymous referee for his valuable comments.

\section{References}

Achache, J., J. L. Le Mouël, and V. Courtillot, Long-period geomagnetic variations and mantle conductivity: An inversion using Bailey's method, Geophys. J. R. Astr. Soc., 65, 579-601, 1981.

Banks, R. J., Geomagnetic variations and the electrical conductivity of the upper mantle, Geophys. J. R. Astr. Soc., 17, 457-487, 1969.

Banks, R. J., The overall conductivity distribution of the Earth, J. Geomag. Geoelectr., 24, 337-351, 1972.

Constable, S., Constraints on mantle electrical conductivity from field and laboratory measurements, J. Geomag. Geoelectr., 45, 707-728, 1993.

Currie, R. G., The geomagnetic spectrum-40 days to 5.5 years, J. Geophys Res., 71, 4579-4598, 1966.

Ducruix, J., V. Courtillot, and J. L. Le Mouël, The late 1960's secular variation impulse, the eleven year magnetic variation and the electrical conductivity of the deep mantle, Geophys. J. R. Astr. Soc., 61, 73-79, 1980.

Malin, S. R. C. and A. M. Iş1kara, Annual variation of the geomagnetic field, Geophys. J. R. Astr. Soc., 47, 445-457, 1976.

Malin, S. R. C., D. E. Winch, and A. M. Işıkara, Semi-annual variation of the geomagnetic field, Abstracts of the 13th Workshop on Electromagnetic Induction in the Earth, Onuma, Hokkaido, Japan, 1996.

McLeod, M. G., Signals and noise in magnetic observatory annual means: Mantle conductivity and jerks, J. Geophys. Res., 97, 17,261-17,290, 1992.

McLeod, M. G., Magnetospheric and ionospheric signals in magnetic observatory monthly means: Electrical conductivity of the deep mantle, $J$. Geophys. Res., 99, 13,577-13,590, 1994.

Nakagawa, T. and Y. Oyanagi, Analysis of Experimental Data by LeastSquare Methods, 206 pp., Univ. Tokyo Press, 1982 (in Japanese).

Roberts, R. G., The long-period electromagnetic response of the Earth, Geophys. J. R. Astr. Soc., 78, 547-572, 1984.

Schultz, A. and L. C. Larsen, Analysis of zonal field morphology and data quality for a global set of magnetic observatory daily mean values, $J$ Geomag. Geoelectr., 35, 835-846, 1983.

Schultz, A. and L. C. Larsen, On the electrical conductivity of the midmantle-I. Calculation of equivalent scalar magnetotelluric response functions, Geophys. J. R. Astr. Soc., 88, 731-761, 1987.

Shankland, T. J., J. Peyronneau, and J.-P. Poirier, Electrical conductivity of the Earth's lower mantle, Nature, 366, 453-455, 1993.

Tukey, J. W., Introduction to today's data analysis, in Proceedings of the Conference on Critical Evaluation of Chemical and Physical Structural Information, edited by D. R. Lide, Jr. and M. A. Paul, pp. 3-14, National Academy of Sciences, Washington, 1974.

Y. Honkura (e-mail: yhonkura@geo.titech.ac.jp) and M. Matsushima (e-mail: mmatsush@geo.titech.ac.jp) 